\title{
Assessment of the level of readiness of future teachers to create psychological safety in the educational environment
}

\author{
S.A. Tyurenkova ${ }^{1 *}, A . V$. Shumakova $^{2}$, and N.I. Tsvirko ${ }^{3}$ \\ ${ }^{1}$ Stavropol State Pedagogical Institute, Stavropol, Russia \\ ${ }^{2}$ Stavropol State Pedagogical Institute, Stavropol, Russia \\ ${ }^{3}$ Stavropol State Pedagogical Institute, Stavropol, Russia
}

\begin{abstract}
A wide range of potential risks and threats in each educational activity segment determines the need to create the safety of educational subjects. It requires improving teachers' training to create a safe educational environment and the formation of a safety culture in the younger generation. As a vital component of the educational environment's integrated safety, the authors of the article consider psychological safety, in the provision of which the professional and personal competencies of the teacher in the field of self-regulation, self-government, and selfdevelopment play a unique role. The study aims to assess the level of neuropsychic stability of students of a pedagogical higher educational institution and identify the degree of development of their ability to selfgovernment. The article presents the results of an empirical study of these indicators. More than 300 students - future teachers who are in different years of their studies - took part in the survey, which made it possible to assess the dynamics of the competencies formation. The data obtained made it possible to determine the directions for improving the institute's work in the formation of the future teachers' competencies necessary to create and maintain a safe, educational environment.
\end{abstract}

\section{A problem statement}

Socio-economic instability, global transformation processes, the pandemic caused by the coronavirus infection COVID-19 have identified at the worldwide level the problem of safety in all spheres of society, including the field of education. These negative phenomena have actualized the necessity of creating a safe educational environment for which a modern teacher should be prepared. The ability to create the educational environment's comprehensive safety is a crucial vector of state policy. The problem of life safety of subjects is becoming a need, both for individuals and for the entire civilization.

In modern society, which the famous German sociologist U. Beck defined as a "risk society" [1], there is an acute problem of creating and maintaining a safe educational environment. However, in the conditions of a dynamically changing society in each

\footnotetext{
*Corresponding author: prof-ped.gpa@mail.ru
} 
segment of educational activity, there is a relatively wide range of potential dangers, various kinds of risks and threats that teachers must be able to allocate and identify resources (environmental and personal) to minimize possible losses. These risks include:

- the interdepartmental disunity of people who are responsible for the safety of the educational environment, insufficient development of the theoretical and methodological foundations for creating a safe educational environment by a teacher (teaching staff);

- the growth of psychological tension due to the instability of the economic and financial situation in the society; an increase in stressful situations in the community, between the members of the teaching staff, in families; an increase in psychological tension due to an increase in the feeling of social insecurity;

- the manifestation of existential disorientation of the personality, withdrawal into virtual worlds, a tendency to self-destructive behaviour, high susceptibility to addictions and manipulative influences; deterioration of basic health parameters in the absence of physical exertion and the dominance of "screen time"; an increase in the overall growing dependence on gadgets and Internet communications;

- the insufficient elaboration of architectural design and content of a safe developmental environment (a high degree of acoustic and visual aggressiveness; a low level of information accessibility; a large number of psychological barriers to interaction in the community of "teacher-students", "students-students", etc.);

- the high level of anxiety and aggressiveness of students; the use of non-constructive conflict resolution strategies by teachers; the low level of psychological culture of teachers, etc.;

- the complication of the pedagogical activity parameters, its stressful and psychogenic nature, which will require special training of future teachers in terms of their psychoemotional stability and the ability to create a psychologically safe educational environment at schools.

The current situation determines the need for an active search for appropriate pedagogical tools and technologies to create complex multifactorial safety of the educational environment due to risks and new challenges.

All the educational environment's main parameters should be considered by teachers in equilibrium, taking into account their influence on the educational process participants and providing comprehensive security, including ideological, moral, psychological, environmental, informational protection. And this is not only a question of special services and management of a preschool educational institution, school or university. All teachers, without exception, should be able to create a safe developing educational environment and to maintain it in a working condition. Proceeding from this, "a modern teacher should have the necessary professional competencies to protect the subjects of the educational process, ensuring the safety of the educational environment of a general education school" [2].

The wide pedagogical practice shows that the teaching staff is not prepared enough for modelling an educational environment that provides maximum safety and security of children's life and health. Often, difficulties arise in organizing systematic work to develop a person's ability to predict, determine level threats, dangers and plan individual ways of protecting against risk factors. At the same time, the teacher's role in creating and providing the psychological component of a safe educational environment is the most crucial.

The analysis of the results presented in the research works of I.A. Baeva, A.V. Dontsov, I.V. Neprokina, O.S. Nikabadze, O.S. Pogrebnaya, E.S. Slyusareva et al. makes it possible to describe the features that characterize a psychologically safe educational environment:

- the absence of psychological violence in the interaction of participants in the educational process $[3,4]$; 
- the preservation of the mental health of students and teachers [3], the psychological integrity of the subjects of education [4];

- the importance of the educational environment for its participants, due to the establishment of personal and trusting communication [3], constructive interaction between the subjects of the educational process [5];

- the educational environment's ability to withstand psychological threats and risks, its resistance to negative external influences, which is due to the educational organization's openness, the presence of an equilibrium state between spontaneity and structure in it $[5,6]$.

The significant factor in creating and maintaining these characteristics is the developed teachers' competences of self-regulation, self-government and self-development. Selfregulation and self-government allow teachers to control the situation at a given moment in time and enable teachers to form a clear understanding of the mechanisms and stages of activities to create a safe educational environment in an educational institution. Selfdevelopment and striving for improvement contribute to the preservation of interest in the pedagogical activity and, therefore, provide teachers' professional psychological stability. In fact, in the process of training future teachers, it seems much more important to form their ability for continuous improvement and self-education [7], which can be considered as a more successful indicator of a person's readiness for a profession than to train reproductive assimilation of a system of ready-made knowledge and repetition of necessary standard skills [8].

\subsection{The objective of the work}

On the basis of the theoretical analysis of the problem of preparing future teachers to create the psychological component of a safe educational environment, we determined the aim of the study, which was to assess the level of neuropsychic stability (NPS) of students of a pedagogical higher educational institution and the development of their ability of selforganization and self-government. The data obtained made it possible to determine the directions for improving the educational institution's work in the formation of future teachers of the competencies necessary to create and maintain a safe educational environment.

We consider neuropsychic stability as one of the indicators of the quality of a psychologically safe educational environment. The ability of self-organization was viewed as a function of structuring of person's activities and planning its stages, the timing and indicators of their achievement and serving as the foundation of the mental stability of the individual [7].

\section{Results of the research}

The assessment of neuropsychic stability was carried out on the basis of the use of the "Prognoz" ("Prognosis") method (Yu.A. Baranov et al.), which also makes it possible to assess the risk of stress maladjustment and stress resistance of respondents [9]. The indicators of the development of the ability for self-government were determined on the basis of the method "Diagnostics of the level of partial readiness for professionalpedagogical self-development" (N.P. Fetiskin et al.) [10]. The study involved 308 students of Stavropol State Pedagogical Institute. Taking into account the task of identifying the dynamics of the studied indicators in the group of respondents, students of the first, second and fourth years of education were represented in approximately equal numbers. First-year students were chosen as a "blank slate", a kind of "starting point", since the disciplines they master at the institute are mainly represented by their chosen training profile's subject fundamentals. Second-year students begin to study the methodological foundations of the 
upcoming professional activity and have experience in passing various types of educational (introductory) practice, including those involving professional tests. Fourth-year students complete theoretical training in subject disciplines that form the scientific basis of the future teaching of a school subject and methods of teaching them and have experience in several types of school practices. The gender characteristics of the respondents were not taken into account. The research was carried out in the second semester of the academic year to minimize the influence of factors that impact the level of NPS among first-year students of the processes of adaptation to the conditions of education at the higher educational institution [11].

The results of the diagnostics of neuropsychic stability of students based on "Prognoz" ("Prognosis") method are presented in table 1.

Table 1. Level of neuropsychic stability of students of the pedagogical higher educational institution (\%).

\begin{tabular}{|c|c|c|c|c|}
\hline \multirow{2}{*}{$\begin{array}{c}\text { Year in } \\
\text { education }\end{array}$} & \multicolumn{4}{|c|}{ The level of neuropsychic stability based on the scale of "Prognoz" } \\
& \multicolumn{4}{|c|}{ ("Prognosis") method } \\
\cline { 2 - 5 } & Unsatisfactory & Satisfactory & Good & Excellent \\
\cline { 2 - 5 } & $1-2$ & $3-5$ & $6-8$ & $9-10$ \\
\hline 1 year & 23.2 & 50.0 & 25.9 & 0.9 \\
\hline 2 year & 18.3 & 52.9 & 25.9 & 2.9 \\
\hline 4 year & 15.2 & 57.6 & 26.1 & 1.1 \\
\hline Prognosis & Unfavorable prognosis & \multicolumn{3}{|c|}{ Favorable prognosis } \\
\hline
\end{tabular}

The data in the table shows the stability of the indicator describing the proportion of students with a good and high level of NPS in all years of education, which is associated with the dependence of this characteristic on such psychophysiological qualities as strength, dynamism, lability of the nervous system, temperament. At the same time, studies have established the influence to the level of NPS of external factors of organic nature, which affect the adaptive capabilities and emotional-volitional sphere of a person and a social nature, which form the personal and professional environment [9]. These data makes it available to assert the possibility of the dynamics of the level of NPS. Since the unfavorable prognosis about the implementation of professional-pedagogical activity in conditions of constantly acting stress factors (uncertainty of tasks, an increase in the number of professional assignments, a lack of time, an increase in the intensity of professional activity, etc.) concerns only students with an unsatisfactory level of NPS, therefore our attention will be paid to this group of students. The unsatisfactory level of NPS characterizes only the likelihood of a "non-optimal type of response to adverse effects of the professional environment" [9], which can manifest itself in neuropsychic breakdowns, inadequate self-esteem and objective perception of reality, which can pose a threat to the safety of children and teachers in an educational institution. At the same time, carrying out psychocorrective measures, creating favorable personal and professional conditions can increase the level of stress resistance and reduce the risk of maladjustment in stress. In this regard, the formation of the future teacher's emotional and professional stability in the process of studying at a higher educational institution seems to be relevant, possible and necessary $[12,13]$. The decrease in the proportion of respondents with an unsatisfactory level of NPS among the fourth-year students in comparison with the first-year students (by $8 \%$ ), revealed in the empirical research, allows us to characterize the system of psychological and pedagogical training of future teachers that has developed at Stavropol State Pedagogical Institute as effective $[14,15]$. For example, the educational process of SSPI is based on an anthropological approach that corresponds to the principles of contextual learning, creating an environment of advanced development, reflexive-activity transfer, integral living of pedagogical knowledge [16], close integration of psychological 
and pedagogical components of professional training based on dialogue and discussion interaction of students and teachers [17].

Students' ability to self-government was studied in accordance with the chosen method [10] and viewed as a condition for successful professional activity and partial readiness for it in the future. The ability of students to self-government was estimated through the following indicators:

1) Self-assessment of the independence of activities.

2) Ability for introspection and reflection.

3) Ability to self-organize and mobilize.

4) Self-control.

5) Hard work and diligence.

All indicators were assessed by the respondents themselves, based on their ideas about the specifics of future activities and personal social success, and correlated with general ideas about the social nature of actions [18]. For each of the five indicators, the average value was estimated and formed as the basis of the averaged data of the total assessment of the level of development of the described competence. The data on the average indicators of the component as a whole is given in table 2 .

Table 2. Average indicators of the formation of individual positions of the component "ability to selfgovernment" among students of the pedagogical higher educational institution.

\begin{tabular}{|l|c|c|c|c|}
\hline \multirow{2}{*}{ Indicators } & \multicolumn{3}{|c|}{ Students' indicators evaluation } \\
\cline { 2 - 5 } & $\begin{array}{c}\text { 1-st year } \\
\text { students }\end{array}$ & $\begin{array}{c}\text { 2-nd year } \\
\text { students }\end{array}$ & $\begin{array}{c}\text { 4-th year } \\
\text { students }\end{array}$ & Average \\
\hline $\begin{array}{l}\text { Self-assessment of the independence of } \\
\text { activities }\end{array}$ & 3.72 & 5.12 & 5.68 & 4.84 \\
\hline Ability for introspection and reflection & 3.96 & 5.42 & 5.96 & 5.11 \\
\hline Ability to self-organize and mobilize & 4.2 & 5.3 & 5.72 & 5.07 \\
\hline Self-control & 4.28 & 5.21 & 5.6 & 5.03 \\
\hline Hard work and diligence & 3.04 & 5.35 & 5.74 & 4.71 \\
\hline Total & $\mathbf{1 9 . 2}$ & $\mathbf{2 6 . 4}$ & $\mathbf{2 8 . 7}$ & $\mathbf{2 4 . 7 6}$ \\
\hline
\end{tabular}

From the data given in table 2, we recorded positive dynamics confirming the influence of the stages (stage 1 - subject training; stage 2 - training in methods of teaching; stage 3 activities of students during practical training at schools) and the level of mastering of the training programme implemented at the educational institution by bachelor students. However, the total indicator's growth by the end of the training does not reach the highest expected values. In particular, according to the method, with the maximum possible indicator of 45 points, the range is the following:

- 0-19 points are considered as low;

- 20-31 points - average;

- 32-45 points - high [10].

It is necessary to point out that first-year students have a threshold value of the formation of the described ability (approaching the border between the low and medium levels).

For first-year students, one of the most challenging components of the ability to selfgovernment turned out to be the position of "hard work and diligence", the difficulties they identified can be formed into a causal list as follows: "it is difficult to make efforts systematically", "it is difficult to concentrate on one process for a long time", "I plan to get a quick result", "I lose interest in multicomponent activities". The students rated their selfcontrol capabilities most highly, correlating them with control, compliance with social norms of behaviour and their agreement with these norms and their implementation possibilities. 
Second-year students put forward the indicator "self-assessment of the independence of activities" as a problematic position, indicating that they are often inclined to overestimate their assessment of self-reliance based on success in routine, repeated activities, while in new circumstances, even regular activities stated that they were more likely than initially thought to seek help from a teacher or group tutor. The respondents in this group rated their abilities for introspection and reflection relatively high. Many educational psychologists highly appreciate the role of reflection in the formation of the teacher's personality $[19,20]$ and the subsequent success of his professional activity. It should be noted that the depression indicators in this sample of respondents are the lowest among all the groups described, which, in our opinion, indicates greater reliability of the data (due to their less variability) obtained from these study participants.

Fourth-year students identified the indicator of the investigated component of "selfcontrol" as problematic. Although this group of respondents' assessment is higher than all average indicators of positions in the other two groups of respondents, they assess their capabilities in "real" activities in the course of their teaching practice. Like second-year students, the respondents of this group evaluated their introspection and reflection abilities most highly. In our point of view, this tendency indicates the factor that these respondents have already studied the basic disciplines of the psychological and pedagogical cycle, and this group of students has completed various types of educational and school practice. The integral indicators obtained as a result of the study of the students' ability to selforganization and self-government are close to the answers for the positions of second-year students, which can be explained by the fact that the number of first and second-year students in the study was $70 \%$ of the total number of respondents.

\section{Conclusions}

Summarizing the results of the theoretical analysis, we came to the following conclusions: 1) psychological safety is a crucial component of the comprehensive safety of the educational environment, in which the professional and personal competencies of teachers in the field of self-regulation, self-government and self-development play a special role; 2) the level of NPS is one of the factors of the predicted effectiveness/inefficiency of the process of formation of self-regulation competencies and the professional stability of future teachers; 3 ) the ability to self-government is a condition for successful professional activity which has an integrative characteristic, including indicators of the independence of teachers' activities, the ability to self-analysis and reflection, self-organization and mobilization, self-control, as well as hard work.

The results of the empirical research allow us to point out the following: 1) senior students (fourth-year students) have higher indicators of NHS and the ability to selfgovernment: $8 \%$ and $9.5 \%$, respectively, higher compared to the indicators of first-year students; 2) the indicator "ability to self-government" is the least pronounced among all components of readiness for professional and pedagogical self-development, which makes us think about the correlation of indicators of the personal development of future teachers and a prospective assessment of their professional success; 3) despite the positive assessment of the system of psychological and pedagogical training provided at the pedagogical higher educational institution, students with an unsatisfactory level of NPS require targeted work to increase their stress resistance. 


\section{References}

1. U. Beck, The Cosmopolitan State, http://www.eurozine.com/article/2001-12-05-becken.html (2001)

2. A.V. Shumakova, V.A. Yashutkin, Methodological foundations of training future teachers to ensure the safety of the educational environment of a comprehensive school, The world of science, culture, education, 5(54), 142-143 (2000)

3. I.A. Baeva, Psychological safety of the educational environment: how to create and measure it, Ecopsychological research - 6: ecology of childhood and psychology of sustainable development, 6, 280-284 (2020)

4. E. Slusareva, A. Dontsov, Psychological Safety of an Inclusive Educational Environment: Criteria, Content and Assessment Methods, Te 2nd International Conference on Contemporary Education and Economic Development, 236-242 (2019)

5. O.S. Nikabadze, O.S. Pogrebnaya, Psychological safety of the educational environment as a condition for psychoemotional stability of participants in the educational process, Stavropol State Pedagogical Institute Bulletin, 17(1), 170-177 (2020)

6. I.A. Stepanova, I.V. Neprokina, Some aspects of providing the psychological safety of the educational environment of a preschool educational organization, Innovative Science, 2-4(14), 120-124 (2016)

7. N.I. Tsvirko, S.A. Tyurenkova, Kant, Development of students' ability to selfeducation as a factor in the effectiveness of educational and future professional and pedagogical activities, 3(28), 94-99 (2018)

8. M.Kh. Rabadanov, Formation of the readiness of bachelors for self-education as one of the most important indicators for assessing learning outcomes, The world of science, culture, 3(76), 210-212 (2019)

9. V.V. Belov, A.V. Korzunin, V.V. Yusupov, D.V. Kostin, Methods for assessing the neuropsychic stability of military personnel, Pushkin Leningrad State University Bulletin, 3, 75-88 (2014)

10. N.P. Fetiskin, V.V. Kozlov, G.M. Manuilov, Socio-psychological diagnostics of the development of personality and small groups (2005)

11. E.A. Volsgunova, E.A. Shereshkova, Coping strategies and neuropsychic stability of bachelors of the Pedagogical University, Psychological and pedagogical search, 2(54), 123-133 (2020)

12. N.V. Uvarina, A.V. Savchenkov, Emotional stability as the most important component of a teacher's professional stability, South Ural State University Bulletin. Issue: Education. Pedagogical Sciences, 2, 36-46 (2019)

13. M. Lee, R. Pekrun, J. Taxer, P. Schutz, E. Vogl, X. Xie, Teachers' emotions and emotion management: integrating emotion regulation theory with emotional labor research, Social Psychology of Education, 19, 4 (2016)

14. N.A. Sivolobova, Model of a teacher's readiness to design a safe professional and educational environment, Modern science, 5, 243-246 (2020)

15. E. Slusareva, A. Dontsov, M. Popova, Formation of professional readiness of teachers as a condition of realization of effective inclusive educational practice, ManPower-Law-Governance: Interdisciplinary Approaches Section: Psychological Sciences. Advances in Social Science, Education and Humanities Research, 408-413 (2019) 
16. V.N. Punchik, E.N. Artemyonok, Concepts of strengthening the psychological and pedagogical training of the future teacher, Scientific works of the Republican Institute of Higher Education, 20-1, 132-139 (2020)

17. T.E. Karpovich, Development of the social and professional competence of the future teacher based on the integration of psychological, pedagogical and methodological training of students at the university, Scientific research and education, 2(26), 46-52 (2017)

18. A.A. Petrusevich, E.A. Safronov, Development of a specialist's readiness for professional activity as a pedagogical problem, The world of science, culture, education, 1(80), 140-142 (2020)

19. I.N. Avdeeva, V.V. Manuylenko, Formation of psychological readiness of pedagogical specialties' students for professional activity, Humanities and pedagogical education, 4, 136-139 (2019)

20. A.V. Trukhin, Readiness for self-educational activity in the psychological and pedagogical aspect, Modern pedagogical view, 8(21), 45-55 (2018) 